\title{
Sinema Felsefesine Giriş: Film-Yapımı Felsefe - Serdar Öztürk \\ İnceleyen: Süreyya Çakır
}

\begin{abstract}
Sinema Felsefesine Giriş: Film-Yapımı Felsefe
\end{abstract}
Yazar: Serdar Öztürk

Ütopya Yayınevi, Ankara: 2018, 392 s.

ISBN: 9786059378352

Serdar Öztürk' ün Ütopya Yayınları' ndan çıkan “Sinema Felsefesine Giriş: Film-Yapımı Felsefe" adlı sinema-felsefe ilişkisine odaklanan kitabı, ilginç bir karşılaşma vesilesi oldu benim için!...Yaslandığı Deleuzyen kavramsal çerçeveyle uyum içinde akademik yazının çizgisel modelinin dışına taşan çatallı üslubu ile, biçimsel açıdan art zamanlı değil baştan sona kavramlar ve filmsel örneklerle birbirinin içine geçen, eşzamanlılık ve akışa dayalı rizomatik yapısı ile, sunduğu zengin kavramsal çerçeve ve filmsel örnekler arasındaki diyalojik ilişkilenme biçimindeki ustalıkla, verili kuşatılmışlıklarımız ve çerçevelenmişliklerimizin dışına çıkmamıza ve yeni olasılıklara imkan açan karşılaşma imkanları üzerinde durması ile...

Düşünümsel doğaları nedeniyle sinemanın -en azından "yazarın deyişiyle "düşünceyoğun sinema" nın- kendi başına felsefe yaptığı iddiasından yola çıkarak felsefe ile film arasındaki ilişkinin sorunsallaştırıldığı bu çalışma, filmin felsefesi/film içinde felsefe yaklaşımından farklı olarak "felsefe olarak film" yaklaşımını temel almakta ve bunu "filmyapımı felsefe" olarak kavramsallaştırmaktadır. Felsefenin sözlü, yazlı ve sinematik olmak üzere üç türlü yapıldığı temel argümanına sahip olan kitapta, sinematik tarzda yapılan felsefe "film-yapımı felsefe" olarak nitelendirilmektedir. Bu çerçeveden hareketle geliştirilen ve filmlerin kendisinin felsefe yaptığını öne süren "film-yapımı felsefe" anlayışı; dinamik, yaratıcı ve her şeyden önemlisi filmin içkin doğasından beslenen bir sinema anlayışı ortaya koymaktadır. Çalışmada benimsenen "Film-yapımı felsefe" yaklaşımı; felsefe ile film arasında felsefe lehine kurulan hiyerarşik bir ilişkiden hareketle sinemanın ikincilleştirildiği, felsefenin sinemayı öncelediği ve dolayısıyla sinemanın indirgendiği bir bakma biçiminin sınırlılıklarını aşma imkânı sunar. Bergson, Ranciere, Badiou, Cavell, Kracauer ve özellikle Deleuze ve Guattari felsefesi ile bağlantılı kavramlar üzerinden sinema-felsefe ilişkisinin tartışıldığı bu çalışma, film-yapımı felsefe yaklaşımı çerçevesinde sinema felsefesinin olanaklarını tartışır; film yapımı felsefenin, filmin kendi anlatım olanakları ile bağlantılı, özgün ve düşünce imal eden - dolayısıyla kendisi felsefe yapan- yaratıcı ve özgürleştirici potansiyelleri üzerinde durur.

Farklı filmlerden hareketle geliştirilen giriş bölümü, klasik akademik yazım biçiminden farklılaşmakta, filmlerden örneklerle bir hayli yaratıcı, özgün ve aforizmalar niteliğinde parçalı bir yazın biçimi geliştirerek çalışmanın nihai hedefi olan "film-yapımı felsefe" nin olanaklarına giriş niteliği taşımaktadır. Bu bölümde filmsel örnekler eşliğinde hareket-zaman bloklarından oluşan sinematik evrenin ontolojisinin gerçek-düş ayrımının sınırlarını aşındırması, düş ile gerçek arasında çatallanmalar yaratarak düşünce üretmesi; hareket-zaman bloklarınca üretilen içeriğin yarattığı imkânlar ve potansiyel düşsel olanaklar 
üzerinde durulur. Kesitler halinde sunulan filmler aracılığıyla, mevcut dünyanın gerçekliğini püskürten ve ondaki katılıkları esneten sinema; kırık çizgiler, fay hatları oluşturan farklı bir görme biçiminin kapılarını aralar; "artık anlam" üretme potansiyeli sayesinde kendi içinde bir "gerçeklik fazlası" ve verili yaşamin ötesine taşan güçler taşır. Öztürk'ün deyişiyle "Sinema, hem hayatın içinde yer alan hem de hayattan taşan unsurları yakalama anlamında verili hayatların dışına çıkan, iki dünya arasında çatallanmalar yaratan, iki dünya arasında gidip gelerek yeni oluşlar yaratan bir felsefe üretmektedir." Öztürk'e göre sinemanın ürettiği felsefe bu temelde yükselmektedir (2018:25).

\section{Nedir Film-Yapımı Felsefe?}

Film yapımı felsefe üzerine tartışmalara odaklanan "Film-Yapımı felsefe Üzerine Tartışmalar" başlıklı Birinci Bölüm, Sinematografik öğelerin orkestrasyonu ile oluşan filmin yeni düşünceler üreterek felsefi düşünmeye katkıda bulunabileceği argümanı temelinde geliştirilir. Filozoflar hakkındaki filmler, felsefi önerilerin somutlaşması olarak filmler, film felsefesi ve felsefe olarak filmler olmak üzere sinema felsefesindeki dört farklı bakma biçimi, farklı filmlerden örnek ve açıklamalarla ele alınır. Felsefe Olarak Film yaklaşımı, Cavell ve Deleuze' un fikirlerinin devamı niteliğini taşır. Bu yaklaşım, felsefeyi merkezi önemde sinemayı ise onun türevi olarak gören yaklaşıma karşı, filmlerin de kendi tarzında düşündüğü ve felsefe yaptığ1 önermesini kitabın temel önermesi olarak sorunsallaştırılır ve bunu farklı film örnekleriyle somutlaştırır.

Felsefenin etik, epistemoloji gibi temel meselelerinin filmsel imajlara uyarlanması olan ve felsefenin sinemayı öncelediğini varsayan Film felsefesi yaklaşımının ötesinde, Filmyapımı felsefe sayesinde sinema, felsefi düşünceleri, meseleleri imajlarla kopyalayan bir sanat olmanın ötesine geçerek bunları yeni bir bireşim içinde aşacak sunumu içerir ve "bizzat düşünülmeyen şeyleri imajlarla icat eden, yaratan, kendi tarzında felsefe yapan bir içeriğe" sahip olur (Öztürk, 37). Bize bir deneyim yaşatan açık uçlu sinematografik imajlar vesilesiyle duygulanım ve düşünümsellik içine gireriz. "İmajlar bizlere çarptığında oluşan duygulanım, sadece bilgi düzeyinde anladı̆̆ımız fikri bize imgesel düzeyde hissettirebilir ve fikir değişik çatallanmalarla değişik fikirlere yol açabilir." (Öztürk, 53-54).

$\mathrm{Bu}$ bölümde, Film-yapımı felsefe tartışmalarında üzerinde durulan illüstrasyon, belirsizlik gibi problemler film örnekleri üzerinden açımlanır. Sinemadaki aşk, Sineaşk kavramı çerçevesinde tartışılır. Sineaşk, "[a]şk felsefesindeki aşkın ötesinde gerçek hayattan taşan, çoğul ve hatta birbiriyle uyuşmaz gibi görünen aşkların sinematografik imajda kendini varettiği bir aşk"tır (Öztürk, 87). Kitapta verilen sinemadaki aşk örnekleri ile felsefedeki aşk anlayışının, felsefedeki aşka dair kavramların ötesine taşmanın ve farklı bir aşk anlayışı geliştirmenin mümkün olduğu ve bu yolla filmlerde, sözlü ve yazılı olarak ifade edilmiş filozofik fikri kopyalayan değil onu aşan bir sunumun da olabileceği önermesi geliştirilir. Filmin felsefedeki kavramların basit bir illüstrasyonu olmadığı farklı film örnekleri üzerinden tartışılır. Örneğin, farklı kavramlar altında geliştirilen felsefedeki aşk kavrayışının, sinemada Haneke'nin Amour (2012) filminden hareketle aşılabileceği öne sürülür. Cengiz Aytmatov'un aynı adlı öyküsünden Atıf Yılmaz tarafından uyarlanan ve sinema-edebiyat ilişkisi açısından 
önem taşıyan Selvi Boylum Al Yazmalım filmi (1978) de herhangi bir metnin felsefi illüstrasyonu veya bir edebi metnin illüstrasyonu değil, edebi metni sinematografik tekniklerle ve kendi tarzında ele alan bir yeniden üretimdir. Yaşam, aşk, sevgi, yaşamın anlamı gibi felsefi meseleleri tıpkı yazılı metin gibi kendi tarzında, kendi araçları ile işler. "Bu araçlarla anlatılan fikir ne artık felsefe kitabındaki fikrin ne de edebiyat eserindeki fikrin aynısı olur. O fikir, sinematikleşir, filmin dünyasında bir düşünce haline gelmeye başlar" (Öztürk, 69). Aşka dair farklı filmlerden örnekler, aşk üzerine nasıl farklı felsefi görüşler öne sürülebileceğini gösterir.

\section{Film -Yapımı Felsefenin Olanakları Nelerdir?}

Badio'nün ve Deleuze'ün görüşlerinden yararlanılarak, Film yapımı felsefe yaklaşımı bağlamında ve farklı filmlerden örneklerle sinema felsefesinin olanaklarının tartışıldığ1 "FilmYapımı Felsefenin Olanaklılığı" başlığını taşıyan İkinci bölüm, farklı tarzların birbirinin temsili ya da gölgesi olmadan kendi içkin değerleri temelinde tartışılması gerektiği iddiasını taşır. Felsefe ve sinema, kendileri düşünce üreten alanlardır. Her ikisi de bunu kendi olanakları, yöntem ve teknikleri çerçevesi içinde yapar. Film, filozofik düşünceyi kendi tarzında üretir; kamera hareketi, müzik montaj, çekim, senaryo gibi farklı unsurların bir araya gelmesiyle oluşan bir kompozisyon olarak film, kendine ait tekniklerle ve kendi tarzında yeni düşünceler üretecek biçimde çalışır.

Kitabın temel referans düşünürü Deleuze'e göre düşüncenin üç uğrağı vardır: bilim, sanat ve felsefe. Düşüncenin bu farklı alanlardaki görünümlerinin kendine ait boyutları vardır. Bunların her biri birbiriyle ilişkili olsa da her birinin kendine özgü doğası, kavramsal araçları, teknikleri vardır; ayrıca, her bir medya formunun o forma uygun ifade tarzı ile farklı sanatların kendine özgü belirleyici özellikleri söz konusudur. Deleuze ve Guattari'ye göre felsefe, "kavram yaratma sanatı"dır (Karadağ, 2016: 44). Bilim, felsefe ve sanat arasında hiyerarşik olmayan bir ilişkilenme biçimi vardır ve bir fikir, bilimde, sanatta ve felsefe gibi farklı alanlarda farklı biçimlerde ifade edilebilir, ona göre biçim alır. Kavramlar bu başka alanlarla ilişkisellik içinde inşa edilir. Felsefenin kavram üretimi için diğer alanlara ihtiyacı vardır. "Felsefeci bilim yapmaz ama bilimin yapılandırdığı bir fonksiyon içerisinde verilmemiş olan bir kavramı araştırabilir. Felsefeci sanat yapmaz ama sanatçının üretmiş olduğu algı ve algı ve duyumsama alanının içerisinde yeni kavramlar keşfedebilir" (Batukan, 2016: 72). Dolayısıyla bu alanların her biri kendi araçlarıyla hikâyesini kurarken, kendi yaratıcı faaliyeti içinden birbirine bir şey söyler ve birbirlerinin alanını genişletirler; birbirleri ile ilişkiye girerek ortak bir "zaman-mekân ufku" içinde bir araya gelebilirler. Sinemanın belirleyici özelliği, onun hareket-zaman bloklarından oluşmasıdır. Fikirler ifade edildikleri tarzlarla bağlantı içindedir ve bu tarzı kullanarak hikâyesini anlatır. "Sinema hareket-zaman bloklarıyla hikâyesini anlatır; felsefe kavramlarla hikâyesini anlatır; bilim ise denklemler ve fonksiyonlarla hikâyesini anlatır" (Öztürk, 127). Bilim ve felsefe düşünceye giden yolda kavramlara dayalı olarak katkılarını sunarken, sanat ve özelinde sinema, düşüncenin duyumsal boyutu ile bağ kurmamızı mümkün kılar. Buna göre “Felsefe kavramsal araçlarla sanat ise duyum ve duyguları uyaracak etkili tekniklerle hikâyesini anlatır" (Öztürk, 69). Bu boyut ihmal edildiğinde çevremizdeki nesne ve ilişkiler birer soyutluk alanı içinde kalır. Bu 
soyutluğun dışına çıkmak, yaşamla somut bağlantılar kurmak için sanat gereklidir. Yazara göre sanat özellikle sinema, yaşama inanca dair çağrısıyla dikkat çeker.

Sinematografik imajların sınıflandırılması ve incelenmesinde ve o imajların ürettiği hikâyenin irdelenmesinde diğer disiplinlerle ve kavramlarla karşılaştırma yapmaya imkân veren bir düşünme biçimini öneren Öztürk'ün belirttiği üzere bu karşılaştırmada izlenecek yöntem, filmdeki imajlar üzerinden kavrama doğru yolculuk etmek ve ardından sinematografik imajlara doğru hareket etmek şeklinde olmalıdır. Felsefi kavramları ve meseleleri baştan tartışıp onları filme dayatmak yerine filmdeki imajların duyumuzda bıraktığı izlerden hareketle felsefi kavramlarla bağ kurmak, bu kavramlardan taşan boyutları sinematografik imajlarla ortaya sermek, yeni fikirler ve kavramlara giden yolu açabilir, yeni sorular sorulabilir ve bu yolla sinematografik imaj kavramsal tartışmaya katkı sunabilir. Sinematografik imajları felsefi bir kavram ile titreşime sokmak, hem felsefi kavramın genişlemesine, hem de sinematografik imajın taşan yönleri ile bağ kurmamıza vesile olabilir. Kitapta özellikle aşk felsefesi bağlamında bol bol örnekleri verilen, felsefi kavramlarla sinematografik imajlar arasında titreşimi yakalayan ve ikisi arasındaki farka alan açan bu tür bir karşılaşma, hem felsefeye hem de sinemaya katkı sunabilir. Böylelikle sinematografik imajlarla kavram ilişkilendirilir ve "kavramdan kaçan ve taşan öğeler" ortaya serilebilir:

İmaj ve kavram karşılaşmasının başlangıç noktası kavramdan imaja doğru değil, imajdan kavrama doğru olur. İkinci olarak karşılaşma, kavramı imaja uyarlamak ve kopyalamak için yapılmaz; tam tersine kavramla imaj arasındaki titreşim yaratan unsurları vurgulamak, kavramı kritik etmek, kavramın sinematografik görünümü ile kavramın yazılı olarak tartışıldığı görünümü arsındaki farkları ve benzerlikleri tartışmak ve en nihayetinde sinematografik imajın kavramın daha ötesinde kendi tarzında nasıl imkânlar sunduğunu göstermek için yapılır (Öztürk, 136).

Kitapta belirtilen bir diğer husus, sanatın farklı alanlarında üretilen kavramsal kişilikler'in sinematik tarzda somutlaşmasının felsefeye katkı sunabilecek bir potansiyellik taşımasıdır. Ayrıca sinema, genelleştirmelerin etkisi altında günlük yaşamı ıskalayan felsefeye karşı, gündelik yaşamdaki nesneleri ve ilişkileri görünür hale getirebilir; "umudu" ve "mucizeyi" hissetmemizi sağlayarak düşüncenin olağan akışına müdahale etmek yoluyla felsefeye katkı sunabilir (Öztürk, 139). Yine Öztürk'ün belirttiği üzere, kendi tarzıyla düşünce üretebilen ve düşüncenin normal akışına müdahale ederek felsefe yapabilen sinema, günlük yaşamda bizden kaçan varlıkları, oluşsal bir varoluş içinde yakalayabilir. Sıradan gündelik hayatın içinde gezinen kamera, yaşadığımız gerilimleri, paradoksları, çatışmaları görünür hale getirerek düşündürür ve hissettirir. Sinematik imajların deneyimi esnasında dünya, içindeki varlıklar ve ilişkiler görünür hale gelebilir; böylelikle sinema verili felsefi kavramların sorgulanması ve yeni kavram üretimi açısından da felsefeye katkı sunabilir. "Burada altı çizilmesi gereken nokta, kavramlarla imajlar arasındaki sinematik ilişkilerde virtüel olarak var olmaları, izleyicilerin zihinlerine çarpan imajlar ve imajlara sordukları sorularla kavramları virtüelden edimsele taşımalarıdır; örneğin Deleuze, sinema kitaplarında kristal imaj, itki imaj, zihin imaj gibi kavramları sinemadan üretmiştir" (Öztürk, 142). 
Öztürk, Kraucer'in film kuramından hareketle, film-yapımı felsefenin doğasını biraz daha açımlar, onun verili olanı ifşa edici işlevini ortaya serer. Kamera yalnızca kayıt cihazı değildir; aynı zamanda normalde görülmeyen şeyleri, örneğin yakın çekimle ifşa eder, görünür kılar. Aynı zamanda çıplak gözle görülmeyen büyüklükleri de kamera lensleriyle ifşa eder; bir duygu yaratır. Ayrıca, sinematik imajlarda, "Bilinci afallatan fenomenler" yoluyla da bir "duygulanım-imaj" yaratılabilir. "Bu, sinemanın yaptığı felsefedir, oluşu algılamdan çıkarıp duygulama dahi taşımak" (Öztürk, 171). Yavaş, hızlı, genel, orta, yakın çekim gibi farklı çekim teknikleri arasında gezinerek de varlığın oluş halindeki çeşitli boyutları yakalanabilir; bunlarla gelip geçicilik oluşsal süreç içinde hissedilebilir. Normalde görülmeyen "zihnin kör noktaları"na düşen olaylar ifşa edilebilir. Ayrıca, sinematik teknikler ile günlük hayatta dikkatimizden kaçan "alışılmadık bileşikler, ret ve aşina" şeklindeki üç nesne görünür kılınabilir. Sinema sayesinde günlük hayatta aşina olduğumuz bütünün parçalarını görmek mümkün olabilir. Yine günlük yaşamda görmek istemediğimiz şeyler, reddettiğimiz şeyler sinemada bize kendisini gösterir veya filmler, kanıksadığımız için görüş açımızın dışında kalan şeyleri göstererek aşinalığı bozar. “Oluş halindeki varlık kavramlarla, soyut ve genel ifadelerle, kültürel kodlarla, molar çizgilerle ve nihayetinde önyargılarımızla, hırslarımızla perdelendiğinde sinema kaydedici ve özellikle ifşa edici işleviyle ortaya çıkar" (Öztürk, 186). Öztürk tüm bunların nasıl mümkün olduğunu farklı filmlerden örneklerle ortaya koyar.

\section{Sinematik Deneyimin Doğası}

"Sinematik deneyim" başlıklı üçüncü bölümde, ikinci bölümde ele alınan argümanlar, sinematik deneyim eksenine taşınır. Bilimin, teknolojinin soyutlamaları altında yaşama dair eksik kalan şeylerin, deneyimle tamamlanmaya ihtiyacı vardır. Deneyim, molar çizgilerin tümüyle dışında bir deneyim alanı oluşturmak anlamına gelmez; o, "molar çizgilerin içerisinde moleküler bir oluş haline geçecek kaçış hatlarıyla yolculuktur" (Öztürk, 193). Sanat ve özelde sinemanın, çerçevelendiğimiz molar yapıların dışında kaçış hatları yaratmada ve deneyimle buluşmada önemli bir yere sahip olduğunu belirten yazar, sinematik deneyimin doğasına ilişkin şunları söyler: “Gerçek yaşamı zaman ve hareket bloklarıyla bize sunan imajlar, sinematik tekniklerle bizleri fiziksel yaşamdaki duyusal deneyimin dahi ötesine taşır. Yeni çoğul deneyimler motor-duyu mekanizmamızın dışındaki farkı ve oluşu anlama ve hissetmede hayatidir" (Öztürk 190). Molar çizgilerin sınırları içinde sıkışıp kalmış, peçelenmiş yaşamların ardındaki saklı yaşam parçalarını düşünmek, buna dair farkındalık kazanmak ve bu molar çizgilerin dışında yaşam alanlarını düşlemek, minör kaçış anları yaratmak sinematik deneyimin esasını oluşturur. Farklı sanat alanlarıyla etkileşim içinde olan, onları bünyesine taşıyan bileşik, melez bir nitelik taşıyan sinema, gündelik yaşamdan hareket eder, hayatın bir parçası olarak onun alanını genişletir. Farklı farklı minör hikâyelerle molar sistemin nasıl işlediğini görünür kılan sinema, böylelikle verili dünyayı eleştirme potansiyeli ve minör kaçış hatları yaratmada önemli bir yere sahiptir. Sinema yalnızca hayatın bir parçası değil, "yaşamımızdan taşan şeyleri de yakalar" (208) ve bunu "farkı yoklayarak" yapar diyen Öztürk, bu argümanı filmsel örneklerle de destekler. Yoklamak ise, "taşan şeyleri yakalamak, bir varlığın içindeki farkı anlayabilmek demektir" (Öztürk, 212). Bunu kendi kavramlarımızı 
yokladığımız şeye dayatarak değil, daha ziyade varlığın kendi iç sesi ile bağ kurarak yapabiliriz. Sinema filmleri sayesinde yaşamdaki farklara, çelişkilere, paradokslara, çatışmalara, zıtlıklara, görünmezliklere dair şeylerdeki "yoklama"lara tanıklık edebiliriz. Bu sayede algılanmaz olan algılanır, fark edilmeyen fark edilir hale gelir. Keza, sinema ve felsefe her ikisi de bunu kendi araçlarıyla yapar. "Felsefe kavramlar ile farkı yoklarken, sinema imajlarla farkı yoklar" (Öztürk, 213). Daha önce bilmediğimiz ve algılamadığımız bir şeyi, farkı yakaladığımızda ise düşünceye doğru hareket ederiz; bu noktada sinema bir imkân alanı olarak durur. Bilmeye dayalı bir etkinlik olmayan, "doğruluk ve hakikatten ziyade, varlıkları oluş halinde zamanda ve hareket halinde" (Öztürk, 214) yakalayarak onları ifşa eden sinema, bilim ve felsefenin soyutlaştırmalarına karşı somut olandan hareketle, enformatik nitelikli kanaat' in sınırlarını aşma ve düşünce geliştirme olanakları sunar. Nitekim "Felsefe kavramlar yaratmaya ve aptallığa zarar vermeye dayanır'” demektedir Deleuze (akt. Karadağ, 44). Öyleyse kavram yaratımına dayanan felsefenin temel işlevi "düşüncenin kanılara indirgenmesi anlamına gel"en aptallıkla mücadele olarak öne çıar. "Aptallık, hata yapmaktan farklı olarak bir ayırt edememe durumuna, önemliyi önemsizden, ilginç ve tekil olanı sıradan olandan ayırt edememeye dayanır" (Karadağ, 46). Bilgiden ziyade yaratma ile bağlantılı olan düşünme etkinliği, kanıların aşınmasına hizmet eder. Böylelikle etken bir unsur olarak felsefi bir nitelik taşıyan sinema da, kanaat'in sınırlarını aşma ve düşünce olanakları geliştirme potansiyeline sahip olur.

\section{Her Şey İmaj mıdır?}

Sinemanın hayatla bağının kurulduğu "Sinematik Deneyim" başlıklı bölümde ele alınan ve izleyen bölümlerde de yer yer değinilen sinemasal imajlara dair ortaya konulan yöntemsel yaklaşım, tartışılması gereken bir boyut taşımaktadır. Kitabın sinemaya dair temel yaklaşımı, imaj/görünüş ve gerçek ayrımını reddeden bir çizgide durmakta; "Her şey birbirinin farklı görünüşü olduğuna göre her şey imajdır" (Öztürk,195) düşüncesini taşımaktadır. İkili karşıtlıklara dayalı Kartezyen bakışı aşmak önemli olmakla birlikte, her şeyin, dünyanın imaja indirgendiği bu bakış açısı kendi içinde sınırlılıklar taşımaktadır. "Her şeyin hareket, titreşim, enerji, güç, madde biçiminde farklı görüngülere sahip" olduğu bir çoğulluk içinde titreşerek bir biriyle etkileşim halinde olduğu bir evrenden, aynı tümce içinde tüm farkları silen, "her şeyin imaj" olduğu monistik bir imajlar evrenine nasıl geçilmektedir?" diye sormaktadır (Öztürk, 281). Yine aynı meseleyle bağlantılı olarak "Hareketin, maddenin, ışığın, enerjinin, gölgenin bir ve aynı şeyin farklı görünümlerinin olduğu bir imaj anlayışını" (Öztürk, 370) odağa alan bir yaklaşım bizi fark'1 değil, birlik'i temel alan metafizik bir yaklaşıma götürmektedir. Diğer postmodern düşünürlerden farklı olarak mikro ve makropolitika diyalektiğini ortaya atan Deleuze ve Guattari önemli perspektifler sunmasına rağmen, imajların öznelerarasılık ve toplumsallık sorunu ile ilişkilenme biçimlerini yeterince teorileştirmediğinden, kültürel bir nitelikten çok ontolojik bir bağlama taşınır imaj anlayışı nihai olarak. Bu ontolojik mesele, kültürel bağlam ile ilişkilendirilmeye muhtaçtır. İmajlara köksapsal yaklaşım üretken olmakla birlikte, dünyayı imaja indirgemek dünya ile metafizik düzeyde bağıtlanmak anlamını taşımaktadır. Son kertede, her şeyin idea'lardan oluştuğu Hegel felsefesindeki gibi, her şeyin farklı görünüme bürünmüş imajlar olduğu önermeleri 
benzerlik taşımaktadır. Evet, sinema, temsil sanatlarından değildir, kopya, gölge değildir; sinema sinemadır, ama dünya da aşkın bir nitelik atfedilen imajların kopyası, gölgesi değildir. Sinema kültürün inşa edici, yapısal, maddi unsurlarından biridir, lakin dünyanın da kendi maddi gerçekliği vardır. Bunlar birbirine indirgenemeyecek, birbiriyle karşıtlık içinde olmayan, ama etki yaklaşımının sınırlarına hapsolmadan -sanatın hep bir artık anlam, fazla üretme ve dolayısıyla verili olanı aşma potansiyeli taşıdığı göz önünde bulundurularak birbiri ile ilişkilendirilmeye muhtaç alanlardır. Bunların karşılıklı olarak ilişkilenme biçimleri üzerinde durmak, nasıl birbirinin içine geçen bir oluş sürecinin parçaları olduğunu kavramak gerekir kendi özerklikleri ve bağlantıları içinde. Bu oluşumları temsilin sınırlılığını aşan ancak birini diğerine indirgemeden karşılıklı etkileşimleri içinde ele alan, dinamik ve diyalojik bir yaklaşım daha kavrayıcı görünüyor.

\section{Filmler Nasıl Düşünür? İşe Yarar Bir Şey Filmindeki Çatallanmalar}

Örneklem olarak Pelin Esmer'in İşe Yarar Bir Şey (2017) filminin analiz edildiği bölüm, ilk üç bölümdeki tartışmaların somutlandığı bir nitelik taşımaktadır. Zaman-imaj sinemasının bir örneği olarak, açık imajlar içeren bir film olarak ele alınan İşe Yarar Bir Şey filminin çözümlemesi, film ile diyalog içinde gerçekleşen, yorumsama alanı geniş olan bir okuma denemesidir. Birinci ve ikinci bölümlerde geliştirilen kavramsal ve kuramsal tartışmaların ve Sinefilozofik yaklaşımın somutlanmasının oldukça yaratıcı bir örneği olarak karşımızda duran bu son derece yetkin analizle, çalışmanın temel iddiası olan sinemadaki imajların da felsefi düşünmeye katkıda bulunabileceği fikri oldukça iyi gerekçelendirilerek somutluk kazanmaktadır. Kavramsal ve biçimsel unsurların diyalojik bir söylemle iç içe geçtiği bir yapı üzerine inşa edilen bu filmin analizi ile sadece biçimi ya da öyküyü merkeze alarak yapılan ya da bir kavramın veya çizilen kavramsal çerçevenin metne uyarlandığı geleneksel analiz yönteminin dışına çıkılmakta; çatallı, biçim ve içeriği iç içe geçiren bir analiz geliştirilmektedir. İmajlar üzerinden kavramlara ve ardından tekrar sinematografik imajlara doğru hareketin temel alındığı bir yöntemle öykünün çizgisel akışının dışına çıkılmakta, çatallı, rizomatik, içiçe geçişlerin ve akışların egemen olduğu bir söylem hâkim olmaktadır. Dolayısıyla örnek film çözümlemesi, kitabın yaslandığı Deleuzyen kavramsal çerçeve ile uyum içindedir. Hâkim yapılar tarafından çerçevelenen hayatlarımız içinde sorgulamanın, taktiklerle bir kaçış/fay hattı yaratmanın, çatlak/yarık açmanın mümkünatını sinematografinin imkânları ile gözler önüne seren, açık uçlu bir okuma örneği, tıpkı değerlendirilmesi yapılan film gibi. Makro yapıların kuşatılmışlığının karşısında özgürlük alanları ve kaçış hatları yaratmada bir filmin nasıl felsefe yapabileceğine, düşünümselliğe nasıl kapı aralayacağına dair sinemanın imkânlarının ipuçlarını sunar analiz. Filmin farklı sekanslarında nasıl bir SineFilozofinin içerildiği serimlenir. İşe Yarar Bir Şey filminin çerçevelenmiş hayatlarla bu hayatlardan kaçış hatları yaratmaya çalışanlar arasındaki çelişki üzerinde durduğunu ve izleyicilere etik sorular sordurtan imaj akışı içinde verili kabuller ekseninde davrananlar ile taktikler geliştirerek kaçış hattı yaratanlar arasındaki çatallanmalar kadar kişinin kendi içinde "virtüel" ve "edimsel" arasındaki çatallanmaları da sinemanın olanaklarıyla etkili bir şekilde verdiğini belirten Öztürk filmin nasıl bir düzlemde, nasıl felsefe yaptığı, nasıl düşündüğü üzerine şunları söyler: "Film, devraldığımız ve normal kabul ettiğimiz pratik/fayacı/öngörülebilir bakışa karşı sanat, 
sezgi ve estetiğin merkezde olduğu ve dilin ampirik sınırlarının ötesine geçen sezgici ve sanatsal bakışı çatıştırır görünür" (273). Filmin zaman-imaj sinemasının bir örneği olarak nasıl karşımızda durduğunu ise şöyle açılar Öztürk:

İşe Yarar Bir Şey'de şiir, ses, müzik, renk, ışık, gölge, yansıma ile yüklü duyular bizleri virtüel ve edimsel düzlemler arasında ima edilmiş bir düş gibi dünya hareketine sokmaktadır. Filmde algıladığımız ilişkiler ve varlıklar şiir, müzik, gölge, ayna, iç ses ve sinematografinin değişik imajlarıla Leyla'nin ima edilmiş düşlerine taşınır. Bir dünya hareketi olarak bu, zamanda ve mekânda çatallanma yaratır. Virtüel ve edimsel olan ikiye bölünür ancak bazen neyin virtüel neyin edimsel olduğunu hissedemeyiz. Geçmiş, şimdi ve gelecek iç içe geçer, kristalize olur. Bu paralize olma durumu artık zaman-imaj sinemasıyla karşı karşıya olduğumuzu anlatır bize (368).

Montaj, kamera hareketleri ve açıları, ses, müzik gibi öğelerle kurulan hareket-zaman blokları ile düşündüren filmin hangi açılardan düşündürdüğünü filmsel öğelerle bağlantısı içinde veren bir çözümleme örneğidir bu bölüm. Sadece öykü anlatmayan, felsefeden farklı olarak bir filmin, sinematik düşünme biçiminin kendine içkin doğası olan imajlarla nasıl felsefe yaptığı üzerine biçim ve öykünün iç içe geçtiği bir örgüye sahip olan bu çözümlemeyi, sadece öyküyü ya da biçimi merkez alan geleneksel yaklaşımlara karşı "SineFilozofik bir yanit" olarak değerlendirir Öztürk.

Nihai olarak, kitap, yola çıkış iddiasını gerçekleştiren, düşünceyi kışkırtan boyutları olan, konvansiyonel sınırları zorlayarak düşünümsellik alanımızı genişleten, sinema üzerinden dünyayı anlamlandırma imkânlarımızı genişletirken aynı zamanda ülkemizde bu alandaki boşluğa yerleşen oldukça yetkin bir çalışma. Sinema felsefesi alanında çalışmalar artmış olsa da, meseleyi film yapımı-felsefe yaklaşımı dahilinde tartışan az sayıdaki eserlerden biri olan bu kitabın yeni üretimlere vesile olması dileğiyle!

\section{Kaynakça}

Batukan, C. (2016). “Bir Kavram Sintesayzırı Olarak Felsefe”, Cogito, sayı: 82, Kış.

Karadağ, İ. (2016). “Deleuze ve Aptallık”, Cogito, sayı: 82, Kış.

Öztürk, S. (2017). Sinema Felsefesine Giriş: Film- Yapımı Felsefe, Ankara: Ütopya Yay. 